\title{
Participação Arriscada: Manifestações e Tumultos em Regimes Ditatoriais*
}

\author{
Abel Escribà-Folch
}

\section{APRESENTAÇÃO}

\begin{abstract}
participação está no centro da democracia, mas, em regimes autoA ritários, encontra-se no centro da mudança política e, infelizmente, do risco. Embora seja óbvio que os níveis de participação são muito mais baixos em regimes ditatoriais do que em democracias, é importante investigar o que leva as pessoas a protestar contra o regime mesmo sendo essa atividade estritamente proibida e altamente perigosa, dada sua importância na configuração do futuro sistema político e de suas condições atuais.
\end{abstract}

Apesar de as ditaduras serem caracterizadas sobretudo por uma quase total concentração de poder ${ }^{1}$, o exercício desse poder não é inteiramente ilimitado, como afirmam muitos autores ${ }^{2}$. O governante em exercício tem de enfrentar alguma limitação imposta por certo nível de lealdade necessária para que permaneça no cargo. Como dizem Rose e Mishler (2002:1), “um tanto de apoio popular é necessário para que o regime sobreviva - seja ele democrático ou não". Nesse sentido, o nível de protesto existente em um regime dado pode indicar indiretamente $o$

\footnotetext{
* Gostaria de agradecer a Tània Verge e aos pareceristas anônimos da revista DADOS os comentários úteis a este artigo. Os erros que permaneceram são meus. [Tradução do original em inglês, "Risky Participation: Demonstrations and Riots under Dictatorial Regimes", de Plínio Dentzien.]

DADOS - Revista de Ciências Sociais, Rio de Janeiro, Vol. 51, nº3, 2008, pp. 719 a 750.
} 
nível de apoio que ele tem na realidade e pode então ajudar o ditador a resolver o que Wintrobe (1998) chama de "dilema do ditador", ou seja, o problema de informação sobre o nível de apoio que possui.

A participação é custosa, não importa onde ocorra, ainda que obviamente o seja mais em ditaduras, na medida em que os direitos políticos são severamente limitados ou simplesmente não existem. Mesmo nesse contexto, as pessoas vão às ruas e demandam, por vezes violentamente, melhores condições econômicas ou um regime mais democrático. Assim, qual é o cálculo por trás da decisão que envolve tantos riscos? Quais são as principais variáveis na explicação dos diferentes níveis de protesto em países governados por líderes autoritários?

Neste artigo, é proposto um modelo geral para dar conta dos protestos violento e não-violento em regimes autoritários ${ }^{3}$. Assim, vários fatores são considerados e testados, ou seja, não é analisada apenas a relação repressão/protesto (para a qual existe uma literatura considerável, embora não focada em ditaduras), mas também as condições econômicas, as trincheiras institucionais estabelecidas pelo regime, a relação entre atividades não-violentas e violentas, a temporalidade, a difusão e os fatores estruturais.

Para responder a essas questões gerais, este texto está dividido da seguinte forma: na primeira seção, são apresentados os principais debates teóricos, bem como as diferentes hipóteses, dividindo os fatores causais em seis grupos principais: instituições; fatores estruturais; condições econômicas; repressão; efeitos temporais e de substituição (entre atividades violentas e não-violentas); e, finalmente, difusão política. A seção seguinte descreve brevemente as variáveis dependentes e independentes utilizadas nas análises empíricas posteriores e sua fonte. Apresentados os dados, na terceira seção, são relatados os principais resultados, bem como os métodos utilizados para obtê-los, mostrando quais são os principais fatores na determinação dos níveis de protesto em regimes não-democráticos. A última seção resume as principais descobertas derivadas da análise quantitativa.

\section{TEORIA E HIPÓTESES}

Neste artigo, trato de manifestações contra o regime e de tumultos, pois constituem as formas mais importantes de participação envolvendo, respectivamente, não-violência e violência ${ }^{4}$. Para dar conta dessas 
duas atividades, o estudo se concentra nos grupos de determinantes listados anteriormente.

\section{Instituições em Ditaduras}

Embora concentrem todo o poder, ditadores não estão totalmente seguros em seus cargos. Posições de privilégio podem gerar inveja, ódio ou dissimulação; assim, em geral os ditadores têm de lidar com ameaças advindas da própria família, dos membros da elite ou da sociedade. Segundo Gandhi e Przeworski (2006; 2007), os ditadores criam partidos e legislaturas para mobilizar a cooperação e cooptar a oposição ${ }^{5}$. Por meio dessas instituições, dirigentes autoritários dão à oposição certo acesso ao processo de tomada de decisões, ao mesmo tempo que distribuem favores e privilégios. De fato, para os regimes comunistas de partido único, Schnytzer e Šušteršič afirmam que "o número de membros do Partido Comunista pode ser usado como indicador de estabilidade política. Entrando no partido, as pessoas contribuem para a estabilidade do regime de partido único e, desse modo, apóiam efetivamente a liderança autoritária" (1998:119).

Todos os estudos sobre dissensão e protesto têm negligenciado sistematicamente essa variável institucional importantíssima e, por conseguinte, o papel que tanto a cooptação quanto a organização da oposição podem desempenhar na determinação de sua capacidade de mobilização. A habilidade que os ditadores têm de prolongar sua permanência no poder por meios outros que não a repressão é, assim, amplamente subestimada, limitando nossa compreensão do assunto.

Quais são, então, os efeitos esperados dessas instituições nos níveis de protesto? De fato, há duas opções muito diferentes. A primeira hipótese seria, à primeira vista, a mais intuitiva, ou seja, se as instituições efetivamente cooptam a oposição, canalizam as demandas dos cidadãos e ampliam o controle do regime sobre a população, o número de manifestações e tumultos será reduzido porque mais benefícios são obtidos pela colaboração com o regime. Nas palavras de Gandhi e Przeworski, “a oposição legalizada se torna a oposição domesticada" (2007:1283).

Alternativamente, a hipótese da "tolerância" prediz o resultado oposto, ou seja, onde essas instituições tiverem sido criadas o nível de protesto será mais alto, dado que a força da oposição já é grande. Nesse caso, incluir a oposição na estrutura do regime implicaria duas questões. Primeiramente, quando algum nível de pluralidade é permitido 
(ainda que pelas razões mencionadas anteriormente), supõe-se que o nível de tolerância do regime também aumente e que, em conseqüência, cresçam os níveis permitidos de protesto. Em segundo lugar, quando a oposição é integrada às instituições ou é permitido que ela crie seus próprios partidos, sua capacidade de organização ou seus recursos aumentam consideravelmente, facilitando o desenvolvimento da participação e das atividades de protesto. De acordo com a abordagem da mobilização de recursos e partindo da suposição de que ações do movimento são racionais, o conflito existente levará a agrupamentos sociais se tiverem lugar mudanças de recursos, de organização de grupo e de oportunidades para a ação coletiva (Jenkins, 1983). Além disso, segundo essa abordagem,

a urbanização, juntamente com o crescimento do capitalismo industrial, os meios de comunicação de massa e a construção de estados modernos, em geral contribuiu para uma mudança de ações reativas, baseadas na comunidade, a ações proativas de associações de larga escala dedicadas a propósitos especiais (Auvinen, 1997:180).

\section{Repressão e Coerção}

A literatura que estuda a relação entre repressão e protesto é abundante. O núcleo da questão é que "a repressão pelos regimes tanto pode agravar quanto atenuar a dissensão por parte dos grupos de oposição" (Lichbach, 1987:266). Alguns autores propuseram diferentes formas para essa relação, bem como para os diversos efeitos que essa ligação pode ter sobre a relação entre atividades violentas e não-violentas. Esse ponto será discutido mais extensamente a seguir.

Os regimes em geral respondem aos que os desafiam de forma implacável, na expectativa de minimizar a extensão dos desafios futuros (Tilly, 1978). Gurr observou que "a ameaça ou a severidade da violência coercitiva usadas pelo regime aumentam a ira dos dissidentes, intensificando assim sua oposição até um limiar de violência governamental além do qual a ira cede ao medo" (1970:238). Importante contribuição a esse respeito é a de Gupta, Singh e Sprague (1993), os primeiros a incluir e a considerar o regime político uma importante variável interveniente nessa relação. Esses autores argumentam que a repressão fomenta atividades de protesto em democracias, mas as dissuade em maior ou menor medida em não-democracias, em que, portanto, a relação pode ser representada como uma curva em U invertido. Alternativamente, sem distinguir entre tipos de regime, Davis (1999) tam- 
bém afirma que uma relação de curva em U invertido pode ser traçada entre coerção e violência política ${ }^{6}$. Tal descoberta, porém, não se sustenta, se considerarmos outras contribuições (ver Moore, 1998). Francisco (1995), por exemplo, descobre em seu estudo de três $\operatorname{casos}^{7}$ que a hipótese do U invertido tem menos suporte do que a alternativa de sua "reação", que afirma que os dissidentes reagem com força à coerção extremamente dura.

De qualquer modo, há dois problemas que exigem esclarecimento nesse debate. O primeiro tem a ver com a especificação da variável dependente, que em alguns estudos é o protesto não-violento, em outros é simplesmente a violência política ou ainda são ambos. Em minha opinião, essas variáveis devem ser estudadas em conjunto, como defendem outros autores (Lichbach e Gurr, 1981; Lichbach, 1987; Moore, 1998). Ambos os tipos de atividade política não parecem independentes e podem ter alguma relação de complementaridade/substituição que deve ser analisada.

O segundo problema se refere às diferentes variáveis utilizadas como indicadores de repressão. Faz-se necessário distinguir entre regimes e repressão. Embora seja verdade que diferentes regimes tenham diferentes níveis médios de repressão, há também grande variabilidade nos níveis de repressão que podem ser encontrados nos mesmos tipos de regime. Por exemplo, enquanto Gupta, Singh e Sprague (1993) usam diferentes variáveis para os dois tipos de regime, Davis (1999) usa o índice de Gastil de direitos políticos. Uma vez feita a distinção entre regimes, é necessária alguma medida de repressão ${ }^{8}$. Neste artigo, o foco são os regimes autoritários, evitando-se, portanto, esse problema.

\section{Temporalidade e Relação Violência/Não-Violência}

Um protesto do passado exerce influência sobre um protesto atual? Atividades não-violentas se tornam violentas? Ou ocorre exatamente o contrário? Essas são as principais questões a serem resolvidas no que tange à temporalidade e às relações violência/não-violência que permitiriam traçar um esquema simples sobre como o protesto se transforma, se expande e diminui.

Como mencionado anteriormente, a participação em regimes ditatoriais é custosa e, por isso mesmo, pode dar forma à sua própria evolução e a seus padrões. Nesse contexto de participação arriscada, tomar a decisão de participar de protestos pode não ser fácil (há mais custos po- 
tenciais), mas, uma vez que o processo tem início, "os apáticos se tornam politizados, os reformistas se radicalizam e os revolucionários dobram seus esforços" (Lichbach e Gurr, 1981:8). Assim, o processo pode se tornar autogerador e um tanto persistente ao longo do tempo. Gurr e Duvall (1973) descobriram que tanto a extensão quanto a intensidade do conflito passado tinham efeitos positivos indiretos sobre o conflito futuro, embora operando através de tradições. Entretanto, isso se refere a relações de longo prazo que não nos interessam aqui ${ }^{9}$. De fato, Lichbach e Gurr (1981) testaram o argumento da persistência simples e não encontraram evidência em apoio de uma tendência geral em direção a tradições persistentes de protesto. Isso nos leva de volta ao ponto explicado anteriormente: em ditaduras, não esperamos processos de protesto/conflito persistentes ao longo do tempo, mas sim processos autogeradores no curto prazo, ou seja, ondas de protesto de curto prazo e dependentes do tempo.

No que diz respeito à distinção entre atividades não-violentas e violentas e à relação entre ambas, o ambiente ditatorial em análise pode outra vez nos ajudar a definir a ligação concreta e a hipótese. A principal proposição de Lichbach (1987) era de que um aumento na repressão governamental à dissensão não-violenta poderia diminuir a não-violência, mas aumentar as atividades violentas da oposição e vice-versa. Assim, segundo o autor, o protesto não-violento e o violento tendem a ser substitutos. Moore (1998) fornece evidência empírica, que tende a apoiar a teoria de Lichbach, usando testes seqüenciais de dados sobre eventos. Entretanto, em um regime autoritário, essa substituição não pode ser considerada direta e bidirecional. O protesto violento reprimido, ou simplesmente ineficaz, é mais difícil de ser transformado em nãoviolência e de ter continuidade como tal, pois isso não é permitido pelas "autoridades". A substituição oposta é mais provável. Se há uma manifestação não-violenta e o regime usa "porretes" (o que certamente ocorre), ou se há chance real de alcançar um objetivo concreto, a violência se torna a única alternativa e a manifestação provavelmente resulta em tumulto.

\section{Condições Econômicas e Sociais}

A falta de bem-estar material tem sido uma das principais causas do protesto e da revolução em todo o mundo. Tullock (1974) afirma que a participação em tais eventos é determinada pela expectativa de ganho ou de perda pessoais. Da mesma forma, segundo Boix (2004:1), "a vio- 
lência política ocorre quando os ganhos líquidos esperados de seu emprego excedem os ganhos líquidos de aceitar o status quo por parte de alguns atores políticos". Portanto, o protesto envolve custos que podem ser classificados em duas categorias diferentes: 1) custos que derivam de medidas coercitivas ou repressivas por parte do Estado; 2) custos de oportunidade que derivam de dedicar tempo e outros recursos ao protesto (ou seja, produzir ou trabalhar) em vez de adquirir bens econômicos (Grossman, 1991).

Façamos um resumo desses custos e benefícios em termos formais simples. Suponhamos que há dois grupos ou classes principais em uma sociedade: a participação dos ricos na população é $\theta$; portanto, (1- $\theta$ ) é o tamanho da população pobre, em que (1- $\theta)>\theta$ (pois o tamanho da população foi normalizado à unidade). A renda total da classe pobre é $y_{p} \mathrm{e}$ a da classe rica é $y_{r} ;$ em termos de rendas pessoais, $y_{r}>y_{p}$. A renda total da sociedade é $Y$. O regime é uma ditadura comandada pelos ricos, de modo que eles escolhem uma alíquota de imposto $\tau$ e, conseqüentemente, o nível de redistribuição. A fração da renda do país não afetada pelo caos, pela destruição e pela instabilidade que a mudança de regime pode gerar é $(1-\lambda)$. Finalmente, $p$ é a probabilidade de uma mudança de regime por levante popular.

Os pobres têm duas opções: obedecer ao regime autoritário ou ir às ruas e reclamar bens públicos ou um regime democrático ${ }^{10}$. Suponhamos que os pobres atinjam seus objetivos e o regime seja derrubado; então sua utilidade linear seria $\frac{(1-\lambda) Y}{1-\theta}-c$, ou seja, a riqueza restante nessa sociedade seria distribuída entre os pobres de tal forma que cada um receberia (por simplicidade notacional) uma parte igual menos o custo pessoal de ter tomado parte nas atividades de protesto (c). Em contrapartida, se os protestos fracassarem, cada pobre receberá apenas $\frac{(1-\lambda) Y_{p}}{1-\theta}-c$, ou seja, a parte restante de sua renda menos o custo de ter participado. Não ter participado de qualquer protesto (qualquer que tenha sido sua forma) produz o seguinte resultado: $y_{p}(1-\tau)+\tau y_{a}$, ou seja, a renda pós-impostos mais uma parte que é distribuída igualmente a partir de gastos governamentais ${ }^{11}$. Portanto, supõe-se que, depois de uma onda de protesto ou mesmo de uma revolução, o regime suprima a parte redistributiva e imponha uma alíquota de imposto mínima. 
Um indivíduo tomará parte em um protesto se, e somente se, a utilidade esperada deste for maior do que a de não participar de qualquer mobilização, ou seja, se:

$$
p\left(\frac{(1-\lambda) Y}{1-\theta}\right)+(1-p)\left((1-\lambda) y_{p}\right)-c>y_{p}(1-\tau)+\tau y_{a}
$$

Podemos derivar nossas hipóteses em relação às variáveis econômicas a partir dessa simples colocação, atentos a qual será o lado da expressão alterado.

As teorias da desorganização social prediziam que o crescimento rápido do Produto Interno Bruto - PIB ou da população geraria protesto e violência política em função do deslocamento social e da mudança estrutural (Huntington, 1968; Olson, 1963). Minha predição é exatamente o oposto, pelo menos em relação ao crescimento econômico (Muller e Weede, 1990). Altos níveis de crescimento econômico implicam um aumento na renda disponível no curto prazo, de tal forma que $y_{p}$ aumenta e o lado direito da expressão principal cresce mais rapidamente do que o lado esquerdo. Portanto, o crescimento econômico reduziria o dissenso.

O nível de redistribuição pelo governo também é importante no modelo. O lado direito da expressão inclui o gasto redistributivo do governo como parte da renda total do indivíduo $\left(\tau y_{a}\right)$; conseqüentemente, quanto mais alto o nível de redistribuição, mais baixo o nível do protesto, pois a opção de não participar se torna mais atraente.

Finalmente, também temos de considerar os efeitos do nível de desenvolvimento, captado pelo PIB per capita, sobre o cálculo da decisão. $\mathrm{O}$ desenvolvimento econômico carrega muitas mudanças estruturais e sociais que podem provocar o dissenso: aumenta o nível de complexidade social, envolve mais industrialização e urbanização; portanto, mais conflitos distributivos e assim por diante. Seguindo nossa simples situação formal, a implicação direta que deveríamos extrair daí seria que um nível mais alto de desenvolvimento implicaria um $Y$ maior; logo, um "bolo" maior para distribuir entre os pobres depois da mudança de regime. Esperaríamos assim uma relação positiva entre PIB per capita e protesto político; porém, essa é apenas a primeira parte da hipótese. Afirmamos que, quando ocorre alguma mudança radical, há sempre algum custo ( $\lambda$ no modelo) no nível da riqueza total na sociedade. Esse custo é uma função positiva do nível de desenvolvimento, de 
modo que $\lambda=\lambda(Y)$, em que $\frac{\partial \lambda}{\partial Y}>0$, e assim, em níveis mais altos do PIB per capita, tal custo aumenta. A hipótese é de que há um determinado limiar a partir do qual esse custo se torna tão alto que não protestar constitui a melhor estratégia, uma vez que os riscos, ao voltar-se contra o regime, são demasiados. Espera-se, portanto, uma relação de curva em U invertido entre PIB per capita e protesto.

Argumento complementar consideraria o efeito da desigualdade sobre o protesto. Segundo a teoria da privação relativa, o dissenso e a violência política resultam da frustração social que aparece quando os resultados experimentados pelos indivíduos são inferiores àqueles que eles esperariam receber ou sentem que mereceriam (Gurr, 1970; Feierabend, Feierabend e Gurr, 1972; Davis, 1999). A desigualdade seria o exemplo mais claro. Em níveis muito baixos de desenvolvimento, quando as economias são em sua maioria agrárias, os níveis de desigualdade e o protesto permanecem baixos. Ao começar o processo de industrialização, a desigualdade aumenta, assim como os conflitos sobre a distribuição. Outra vez, em níveis muito altos de desenvolvimento, a desigualdade, ainda que existente, é mitigada pelo Estado. Esse argumento reforça nossa relação predita em forma de U invertido entre o desenvolvimento econômico e o dissenso ${ }^{12}$.

O caso especial dos Estados rentistas, presentes sobretudo no Oriente Médio e na África, deve também ser considerado como variável de controle. Nesses casos, a abundância de recursos naturais e, conseqüentemente, os enormes fluxos de receita não-provenientes de impostos permitem cobrar tributos da população em níveis muito baixos, distribuir rendas e, como resultado, reduzir o conflito político (Karl, 1997; Smith, 2004). Independentemente disso, a teoria do Estado rentista produz duas outras linhas com conseqüências preditas opostas sobre o dissenso. A primeira desenvolve a proposição de que tal abundância de recursos exploráveis fomenta Estados predadores, maiores conflitos distributivos e, então, a militarização da política ${ }^{13}$. A segunda relaciona rendas maiores ao comportamento de busca de mais rendas e à corrupção. Como diz Okruhlik (1999:297), “a riqueza gerada pelas receitas do petróleo é um catalisador para a oposição ao Estado, mais do que uma ferramenta para aplacar o dissenso, por duas razões. Ela é distribuída de maneira desigual [...] e dá aos opositores potenciais os recursos necessários para a mobilização contra os regimes". 
Por essas razões, espera-se que esses Estados (exportadores de petróleo e de minérios) sofram mais protestos e violência política ${ }^{14}$.

\section{Fatores Estruturais}

Essa abordagem salienta o papel que certas estruturas subjacentes aos países individuais desempenham na determinação dos níveis de protesto e/ou de violência. Em regimes autoritários, dois fatores principais devem ser considerados: o conflito étnico e a herança de instituições prévias.

A teoria da dominância étnica afirma que os controles político e econômico de um grupo hegemônico podem provocar o protesto de grupos menores excluídos. Como se pode facilmente perceber, isso é inteiramente compatível com uma possível sub-hipótese derivada da abordagem da privação relativa mencionada anteriormente.

Há muitos casos em que uma minoria étnica domina outro grupo étnico maior (por exemplo, o apartheid sul-africano). Espera-se que esse segundo grupo seja mais afeito ao protesto e à rebelião dada sua população mais numerosa. Por outro lado, também se tem afirmado que a etnicidade pode ajudar a resolver problemas de ação coletiva na medida em que reduz os custos de informação e facilita a coordenação dos grupos; assim, nas mesmas circunstâncias, a maior homogeneidade étnica tornaria mais prováveis a organização e o êxito do protesto.

Em relação à natureza do regime anterior, durante períodos democráticos, a sociedade civil pode se organizar e participar livremente. Se essa democracia for derrubada, muitos grupos e organizações de outrora tentarão dar continuidade a suas atividades, ainda que clandestinamente. Afinal, certa cultura democrática foi criada, e imaginamos que não seja fácil apagá-la.

Alternativamente, envolvimento em alguma guerra (qualquer que seja seu tipo) também é capaz de aumentar o protesto. O esforço de guerra pode enfraquecer a coerção do regime, ao passo que a instabilidade política pode fazer com que a oposição perceba a existência de um contexto favorável para a mudança de regime (acima de tudo se for uma guerra civil ou interna), aumentando, portanto, o valor de $p$ na expressão mostrada anteriormente. 


\section{Difusão Política}

É possível que surjam protestos internos em países por causa da difusão desses processos pelos países. Ondas de protesto que ocorrem em sociedades próximas podem servir como inspiração ou exemplo de como agir em circunstâncias semelhantes, de tal forma que os movimentos sociais podem ser entendidos "como conjuntos inter-relacionados de processos de difusão" (Oliver e Myers, 1998:2). Ou simplesmente precedentes internacionais podem servir para ampliar o âmbito de potenciais ações empreendidas que não tenham sido consideradas anteriormente por possíveis ativistas diante das mesmas condições econômicas ou políticas ${ }^{15}$.

Um exemplo claro é o da Europa Oriental, em 1989, que levou à disseminação de protestos pró-democracia em muitos países. Bratton e Van de Walle (1997) também mostram que, no continente africano, o protesto era mais freqüente em países com maior número de vizinhos contíguos: "Essa medida supõe que, quanto mais fronteiras internacionais tinha um país, tanto mais sua população seria suscetível a efeitos políticos de manifestação" (ibidem:137). Assim, os tumultos que levaram à derrota da Frente de Libertação Nacional, na Argélia, tiveram grande influência em outros países islâmicos. As demandas por democracia na Costa do Marfim constituíram um bom exemplo para as mobilizações posteriores no Mali, organizadas pelo Committee for Democratic Initiative [Comitê pela Iniciativa Democrática] e pela Alliance for Democracy [Aliança pela Democracia] (Bratton e Van de Walle, 1997).

\section{DADOS E VARIÁVEIS}

\section{Países e Períodos}

O conjunto de dados comparativos em séries temporais, utilizado para testar as diferentes hipóteses, cobre o período de 1950 a 1990 e foi coletado a partir de Banks (1996), do World Development Indicators, do Banco Mundial (The World Bank, 2000), e sobretudo da base de dados $\mathrm{ACLP}^{16}$.

Os países incluídos na análise são: África do Sul, Angola, Argélia, Benin, Botsuana, Burkina Faso, Burundi, Cabo Verde, Camarões, Chade, Comoros, Congo, Costa do Marfim, Djibouti, Egito, Etiópia, Gabão, Gâmbia, Gana, Guiné, Guiné-Bissau, Lesoto, Libéria, Madagascar, Malaui, Mali, Marrocos, Mauritânia, Moçambique, Niger, Nigéria, Quê- 
nia, República Centro-Africana, Ruanda, Senegal, Seicheles, Serra Leoa, Somália, Sudão, Suazilândia, Tanzânia, Togo, Tunísia, Uganda, Zaire, Zâmbia, Zimbábue, El Salvador, Guatemala, Haiti, Honduras, México, Nicarágua, Panamá, República Dominicana, Argentina, Brasil, Chile, Equador, Guiana, Paraguai, Peru, Suriname, Uruguai, Venezuela, Bangladesh, China, Coréia do Sul, Filipinas, Iêmen, Indonésia, Irã, Iraque, Jordânia, Laos, Malásia, Mongólia, Mianmar, Nepal, Paquistão, Cingapura, Síria, Sri Lanka, Tailândia, Taiwan, Alemanha Oriental, Bulgária, Espanha, Grécia, Hungria, Iugoslávia, Polônia, Portugal, Romênia, Tchecoslováquia, Turquia, União Soviética, Fidji e Samoa Ocidental. A amostra pode variar por falta de informações.

\section{Variáveis Dependentes}

As duas variáveis dependentes utilizadas neste artigo são: 1) o número de manifestações, definidas como reuniões públicas pacíficas de pelo menos cem pessoas para o fim específico de exibir ou dar voz à sua oposição a políticas ou à autoridade do governo, excluídas as manifestações de clara natureza antiestrangeira; 2) o número de tumultos, ou seja, manifestações violentas ou embates entre mais de cem cidadãos envolvendo o uso de força física. Ambas as variáveis foram compiladas a partir de Banks (1996).

\section{Variáveis Independentes}

As principais variáveis independentes incluídas na análise empírica buscam capturar todos os aspectos esboçados no referencial teórico anterior e são as seguintes:

- Crescimento econômico: medido pela taxa anual de crescimento da renda per capita. Seguindo o simples modelo descrito, espera-se uma relação negativa entre crescimento e protesto.

- PIB real per capita e seu quadrado, para testar a relação de curva em U invertido.

- Repressão: medida pelo número de expurgos, ou seja, quaisquer eliminações por prisão ou execução de oposição política dentro dos quadros do regime ou da oposição. Para testar a relação não-linear, o quadrado do número de expurgos também será incluído. O número de assassinatos ou de tentativas de assassinato de altos funcionários ou políticos do governo será considerado para testar se a atmosfera de instabilidade gerada aumenta o número de atividades de protes- 
to. Para aferir o nível de repressão por parte do governo, também se utilizou o índice de liberdade política (bem como o quadrado do índice, para captar a não-linearidade potencial do efeito) da Freedom House.

- O número médio de manifestações e tumultos por ano em cada região, a fim de testar a existência de algum tipo de difusão dessas atividades de participação.

- População urbana como porcentagem da população total, para testar as abordagens da mobilização de recursos.

- Composição étnica: porcentagem do maior grupo étnico no total da população.

- Democracia prévia: variável dummy codificada como 1 se o país tiver sido uma democracia em qualquer momento antes de sua entrada na amostra; do contrário, 0 .

- Dispêndio governamental: participação real do governo como porcentagem do PIB (em preços internacionais de 1985). É utilizada como indicador indireto do nível de redistribuição existente no país. Compilada a partir das Penn World Tables.

- Instituições ditatoriais: classificação das ditaduras por instituições: 1) ditadura plenamente institucionalizada, com legislatura e vários partidos; 2) ditadura semi-institucionalizada, com legislatura ou partido único, ou ambos; 3) ditadura não-institucionalizada, sem legislatura nem partidos. A categoria de referência é a primeira.

- País exportador de petróleo: variável dummy codificada como 1 se a proporção média das exportações de petróleo sobre o total em 1990-1993 tiver excedido 50\%; do contrário, 0. Essa variável é incluída para testar a validez do modelo do Estado rentista.

- País exportador de minérios: variável dummy codificada como 1 se a proporção média da exportação de minérios sobre o total em qualquer ano para o qual o país tenha dados tiver excedido $50 \%$; do contrário, 0. Também incluída para testar o modelo do Estado rentista.

- Guerra: variável dummy codificada como 1 se tiver havido guerra de qualquer tipo (internacional ou civil); do contrário, 0 .

- Região: variável dummy. A categoria de referência é “América Latina ou Caribe". 


\section{MODELOS E RESULTADOS: ANÁLISE COMPARATIVA DE SÉRIES TEMPORAIS}

\section{Protestos Violento e Não-Violento em Regimes Ditatoriais}

Não deve surpreender que tenha havido mais tumultos e manifestações contra o regime em democracias do que em ditaduras. De 1950 a 1995, as democracias tiveram uma média de 0,76 manifestação e 0,87 tumulto por ano, enquanto as ditaduras tiveram, respectivamente, 0,49 e 0,50 .

O foco deste artigo está nas formas de participação política (violenta e não-violenta) que têm lugar em regimes autoritários. Uma distinção comum feita entre sistemas autoritários atenta para o tipo de chefe de Estado efetivo. Na Tabela 1, são apresentadas as principais estatísticas descritivas para o período inteiro das duas variáveis dependentes para diferentes tipos de ditador.

Regimes militares enfrentam níveis mais altos dos dois tipos de protesto do que os regimes monárquicos e civis. Os regimes militares têm maior dificuldade em serem aceitos pelos cidadãos, pois lhes falta praticamente qualquer tipo de legitimidade, uma vez que derrubaram o regime previamente existente por um golpe de Estado e passaram a se basear na repressão e na violência. Já os monarcas se baseiam na tradição e em sistemas sociais fechados. Na categoria de ditaduras civis, encontramos uma grande variedade de dirigentes em função dos diferentes tipos de chefe de Estado, que podem incluir, como presidentes "eternos" - indivíduos que alguma vez venceram uma eleição -, chefes do partido governante, líderes personalistas e assim por diante.

Tabela 1

Tumultos e Manifestações por Tipo de Ditadura

\begin{tabular}{|c|c|c|c|c|}
\hline \multirow{2}{*}{\multicolumn{2}{|c|}{ Tipo de Participação }} & \multicolumn{3}{|c|}{ Ditador } \\
\hline & & Civil & Monárquico & Militar \\
\hline \multirow[t]{2}{*}{ Tumultos } & Média & 0,488 & 0,337 & 0,521 \\
\hline & Desvio padrão & 1,879 & 1,341 & 1,507 \\
\hline \multirow[t]{2}{*}{ Manifestações } & Média & 0,381 & 0,167 & 0,536 \\
\hline & Desvio padrão & 1,506 & 0,838 & 1,746 \\
\hline
\end{tabular}

Elaboração do autor. 
Observando diferentes períodos, o maior número de manifestações se concentra durante os anos 1950 e, sobretudo, durante os anos 1980 (0,67 e 0,74 em média, respectivamente). Os anos 1950 compreenderam uma década em que se realizaram muitos dos processos de independência de colônias em diversas regiões, algumas das quais levaram ao estabelecimento de ditaduras e à instabilidade pós-colonial (Gana, Malásia e Cingapura em 1957; Guiné em 1958; Marrocos, Sudão e Tunísia em 1956, e assim por diante). Foi no final dos anos 1980 que aconteceu o colapso da antiga União Soviética e começaram as transições dos antigos países comunistas. O Gráfico 1 mostra as médias anuais de ambos os tipos de protesto político.

O número de tumultos durante essas décadas permaneceu mais ou menos constante; apenas na década de 1960, ele aumenta um pouco, dada a quantidade de processos de independência que ocorreram também nesse período (Argélia, Botsuana, Camarões, Quênia, Gâmbia), alguns dos quais particularmente violentos e seguidos de instabilidade política crônica.

\section{Gráfico1}

Número Médio Anual de Manifestações e Tumultos em Ditaduras

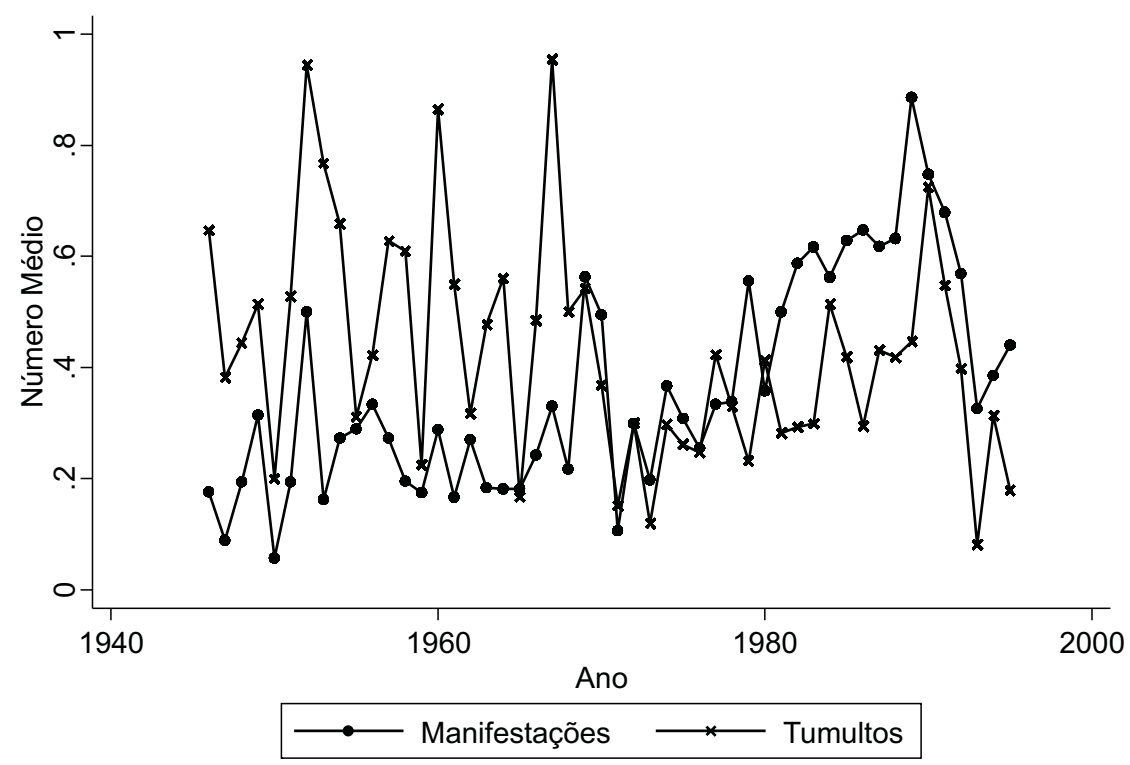

Elaboração do autor. 
Ditaduras experimentam longos períodos de paz e de calmaria social. Entretanto, quando ocorrem episódios de protesto, estes em geral acionam mudanças nas preferências das pessoas que levam a períodos de grande instabilidade (Kuran, 1995). Por exemplo, a China teve 32 tumultos em 1967 e o Zaire 17 durante os anos 1960; a África do Sul teve 26 manifestações contra o regime em 1985 e a Tchecoslováquia 19 no famoso levante de 1969.

\section{Manifestações Contra o Regime}

Dada a natureza comparativa em séries temporais dos dados aqui utilizados, a estimativa dos "modelos de manifestação" foi feita usando os erros-padrão corrigidos do painel de Beck e Katz (1995), incluindo dummies para controlar os efeitos regionais. O modelo de base também inclui a variável dependente com um ano de defasagem para testar se o protesto tenderia a ser um processo autogerador de curto prazo. A Tabela 2 mostra os resultados dos modelos de regressão com especificações ligeiramente diferentes para checar a robustez das estimativas.

Os resultados empíricos confirmam amplamente as principais hipóteses expostas na primeira seção, ou pelo menos ajudam a decidir entre duas delas. O efeito das variáveis econômicas é aquele previsto pelo modelo na subseção Condições Econômicas e Sociais (p. 724) em todos os casos e modelos analisados: o crescimento econômico reduz o nível de curto prazo do protesto ao aumentar a renda disponível pelo povo e, assim, seu bem-estar no regime corrente; ao mesmo tempo, aumenta os custos de oportunidade da participação em tais atividades ${ }^{17}$. Recusa-se, então, a teoria da desorganização social, que predizia precisamente o efeito oposto. O dispêndio governamental, tomado como indicador indireto do nível de redistribuição, também mostra o sinal predito e é altamente significativo, provando que aumentar o bem-estar do povo por meio do Estado também reduz o dissenso. Finalmente, a relação de curva em U invertido entre o nível de desenvolvimento e o número de manifestações também foi confirmada, como mostra o coeficiente negativo e significativo do quadrado do PIB per capita. Isso apóia o modelo apresentado e também a descrição mais geral relacionada às teorias da privação relativa, ou seja, aquela que relaciona o desenvolvimento à desigualdade e esta ao protesto ${ }^{18}$.

Sobre a relação entre repressão e dissenso, as estimativas confirmam os resultados obtidos por Gupta, Singh e Sprague (1993): em regimes au- 
Tabela 2

Manifestações contra o Regime em Ditaduras: Análise Comparada de Séries Temporais

\begin{tabular}{|c|c|c|c|c|c|}
\hline \multirow[b]{2}{*}{ Variáveis Independentes } & \multicolumn{5}{|c|}{ Manifestações contra o Regime } \\
\hline & (1) & (2) & (3) & (4) & (5) \\
\hline \multirow[t]{2}{*}{ Variável dependente defasada } & $0,446^{* * *}$ & $0,501^{* * *}$ & $0,448^{* * *}$ & $0,447^{* * *}$ & $0,501^{* * *}$ \\
\hline & $(0,067)$ & $(0,081)$ & $(0,067)$ & $(0,067)$ & $(0,081)$ \\
\hline \multirow[t]{2}{*}{ Crescimento econômico } & $-0,014^{* * *}$ & $-0,017^{* * *}$ & $-0,015^{* * *}$ & $-0,014^{* * *}$ & $-0,016^{* * *}$ \\
\hline & $(0,003)$ & $(0,004)$ & $(0,003)$ & $(0,003)$ & $(0,004)$ \\
\hline \multirow[t]{2}{*}{ PIB per capita } & $0,0002^{* * *}$ & $0,0002^{* * *}$ & $0,0002^{* * *}$ & $0,0002^{* * *}$ & $0,0002^{* *}$ \\
\hline & $(0,000)$ & $(0,000)$ & $(0,000)$ & $(0,000)$ & $(0,000)$ \\
\hline \multirow[t]{2}{*}{$(\mathrm{PIB} \text { per capita })^{2}$} & $-2,52 \mathrm{e}-08^{* * *}$ & $-2,72 \mathrm{e}-08^{* * *}$ & $-2,40 \mathrm{e}-08^{* * *}$ & $-2,4 \mathrm{e}-08^{* * *}$ & $-2,89 e-08^{* * *}$ \\
\hline & $(8,35 \mathrm{e}-09)$ & $(9,76 \mathrm{e}-09)$ & $(8,23 e-09)$ & $(8,24 \mathrm{e}-09)$ & $(9,79 e-09)$ \\
\hline \multirow[t]{2}{*}{ Média das manifestações regionais } & $0,681^{* * *}$ & $0,757^{* * *}$ & $0,684^{* * *}$ & $0,684^{* * *}$ & $0,757^{* * *}$ \\
\hline & $(0,079)$ & $(0,101)$ & $(0,080)$ & $(0,080)$ & $(0,101)$ \\
\hline \multirow[t]{2}{*}{ Semi-institucionalizadas } & $-0,216^{* *}$ & $-0,379^{*}$ & $-0,205^{* *}$ & $-0,215^{* *}$ & $-0,377^{*}$ \\
\hline & $(0,094)$ & $(0,210)$ & $(0,092)$ & $(0,094)$ & $(0,211)$ \\
\hline \multirow[t]{2}{*}{ Não-institucionalizadas } & $-0,200^{* *}$ & $-0,326^{*}$ & $-0,187^{* *}$ & $-0,201^{* *}$ & $-0,317$ \\
\hline & $(0,096)$ & $(0,194)$ & $(0,095)$ & $(0,096)$ & $(0,196)$ \\
\hline \multirow[t]{2}{*}{ Grupo étnico (\%) } & $0,004^{* * *}$ & $0,004^{* * *}$ & $0,003^{* * *}$ & $0,004^{* * *}$ & $0,004^{* * *}$ \\
\hline & $(0,001)$ & $(0,001)$ & $(0,001)$ & $(0,001)$ & $(0,001)$ \\
\hline \multirow[t]{2}{*}{ População urbana (\%) } & 0,0002 & 0,0005 & 0,0004 & 0,0001 & 0,0007 \\
\hline & $(0,002)$ & $(0,003)$ & $(0,002)$ & $(0,002)$ & $(0,003)$ \\
\hline \multirow[t]{2}{*}{ Expurgos } & $0,233^{* * *}$ & - & $0,237^{* * *}$ & $0,234^{* * *}$ & - \\
\hline & $(0,091)$ & - & $(0,092)$ & $(0,091)$ & - \\
\hline \multirow[t]{2}{*}{$(\text { Expurgos })^{2}$} & $-0,006^{* *}$ & - & $-0,006^{* *}$ & $-0,006^{* *}$ & - \\
\hline & $(0,002)$ & - & $(0,002)$ & $(0,002)$ & - \\
\hline \multirow[t]{2}{*}{ Índice de liberdade política } & - & $0,561^{* * *}$ & - & - & $0,573^{* * *}$ \\
\hline & - & $(0,182)$ & - & - & $(0,185)$ \\
\hline \multirow[t]{2}{*}{ (Índice de liberdade política) $^{2}$} & - & $-0,053^{* * *}$ & - & - & $-0,055^{* * *}$ \\
\hline & - & $(0,017)$ & - & - & $(0,018)$ \\
\hline \multirow[t]{2}{*}{ Assassinatos políticos } & $0,101^{*}$ & 0,095 & $0,109^{*}$ & $0,110^{*}$ & 0,078 \\
\hline & $(0,061)$ & $(0,076)$ & $(0,060)$ & $(0,060)$ & $(0,077)$ \\
\hline \multirow[t]{2}{*}{ Participação do governo } & $-0,011^{* * *}$ & $-0,009^{* * *}$ & $-0,010^{* * *}$ & $-0,011^{* * *}$ & $-0,009^{* * *}$ \\
\hline & $(0,002)$ & $(0,003)$ & $(0,002)$ & $(0,002)$ & $(0,003)$ \\
\hline \multirow[t]{2}{*}{ Democracia prévia } & $0,339^{* * *}$ & $0,434^{* *}$ & $0,353^{* * *}$ & $0,364^{* * *}$ & $0,394^{* *}$ \\
\hline & $(0,125)$ & $(0,174)$ & $(0,129)$ & $(0,127)$ & $(0,173)$ \\
\hline \multirow[t]{2}{*}{ Dummy de guerra } & 0,146 & - & - & - & $0,244^{*}$ \\
\hline & $(0,103)$ & - & - & - & $(0,126)$ \\
\hline
\end{tabular}


Tabela 2

Manifestações contra o Regime em Ditaduras:

Análise Comparada de Séries Temporais

(continuação)

\begin{tabular}{l|c|c|c|c|c}
\hline \multirow{2}{*}{ Variáveis Independentes } & \multicolumn{5}{|c}{ Manifestações contra o Regime } \\
\cline { 2 - 6 } País exportador de minério & $\mathbf{( 1 )}$ & $\mathbf{( 2 )}$ & $\mathbf{( 3 )}$ & $\mathbf{( 4 )}$ & $\mathbf{( 5 )}$ \\
\hline \multirow{3}{*}{ País exportador de petróleo } & $0,151^{*}$ & - & - & $0,140^{*}$ & - \\
& $(0,079)$ & - & - & $(0,077)$ & - \\
Oriente Médio & - & - & $-0,015$ & - & - \\
& - & - & $(0,109)$ & - & - \\
Europa Oriental & 0,024 & $-0,039$ & 0,037 & 0,053 & $-0,096$ \\
& $(0,078)$ & $(0,109)$ & $(0,081)$ & $(0,077)$ & $(0,107)$ \\
África & $-0,075$ & $-0,118$ & $-0,090$ & $-0,074$ & $-0,116$ \\
& $(0,217)$ & $(0,274)$ & $(0,217)$ & $(0,216)$ & $(0,275)$ \\
Sul da Ásia & $0,536^{* * *}$ & $0,661^{* * *}$ & $0,535^{* * *}$ & $0,541^{* * *}$ & $0,660^{* * *}$ \\
& $(0,120)$ & $(0,172)$ & $(0,123)$ & $(0,120)$ & $(0,172)$ \\
Leste da Ásia & $-0,638$ & $-1,054^{* *}$ & $-0,681$ & $-0,658$ & $-1,041^{* *}$ \\
& $(0,414)$ & $(0,529)$ & $(0,416)$ & $(0,415)$ & $(0,527)$ \\
OCDE - Organização para Cooperação & $-0,088$ & 0,821 & $-0,064$ & $-0,053$ & 0,769 \\
e Desenvolvimento Econômico & $(0,567)$ & $(1,153)$ & $(0,566)$ & $(0,565)$ & $(1,140)$ \\
\hline$R^{2}$ & $0,154^{*}$ & 0,165 & $0,162^{* *}$ & $0,179^{* *}$ & 0,123 \\
Wald Chi ${ }^{2}$ & 0,3484 & 0,3928 & 0,3473 & 0,3478 & 0,3942 \\
Observações & $692,36^{* * *}$ & $2410,54^{* * *}$ & $978,97^{* * *}$ & $733,71^{* * *}$ & $3136,85^{* * *}$ \\
\hline & 2.057 & 1.439 & 2.057 & 2.057 & 1.439 \\
\hline
\end{tabular}

Erro padrão entre parênteses; *** $p<0,01 ; * * p 0,05 ;{ }^{*} p<0,10$.

Tipo de regime omitido é "plenamente institucionalizado".

Elaboração do autor.

toritários, não há uma relação não-linear de curva em U invertido entre coerção e dissenso (nesse caso, manifestações). "Repressão" foi medida usando duas diferentes variáveis, "expurgos" e "índice de liberdade política" (evidentemente, só para ditaduras), e ambas dão o mesmo resultado sem alterar consideravelmente os coeficientes das demais variáveis no modelo, como pode ser facilmente checado. O número de assassinatos políticos também foi incluído nos modelos, em uma tentativa de avaliar o nível de instabilidade do regime. O assassinato de um alto funcionário ou político do governo pode ser um indicativo para o povo de que o regime está vulnerável e, assim, alterar o cálculo de sua capacidade repressiva ${ }^{19}$. De qualquer modo, o coeficiente, embora positivo, como predito, só é significativo em três dos cinco modelos, de modo que sua importância é apenas moderada. 
A variável que captura a difusão política do protesto é positiva e altamente significativa em todas as especificações. A média de protestos foi calculada para cada região, uma vez que se supõe que, quanto mais próximos os países, é mais provável que seus efeitos possam se estender às outras sociedades por duas razões principais: 1) a proximidade facilita os fluxos de informação e, portanto, o conhecimento sobre o que está acontecendo em outros países; 2) países na mesma região têm a possibilidade de compartilhar condições econômicas e políticas semelhantes, que podem alimentar o dissenso político. O coeficiente dessa variável é sempre maior do que 0,68.

É claro que, nominalmente, instituições democráticas fazem diferença mesmo em ditaduras, em que são de fato criadas para realizar funções muito diferentes das realizadas nas democracias. Como observado anteriormente, regimes autoritários procuram cooptar a oposição integrando-a ao ambiente institucional, de modo que agrados e privilégios possam ser distribuídos e concessões políticas oferecidas (Gandhi e Przeworski, 2006). Os resultados, porém, parecem bem estranhos. A categoria com o nível mais baixo de protestos é a ditadura semi-institucionalizada e, em seguida, a não-institucionalizada (ambos os coeficientes são significativos ${ }^{20}$. Isso pareceria confirmar a hipótese da tolerância, mas não completamente. O que de fato observamos é uma espécie de relação curvilinear entre o grau de institucionalização do regime e a mobilização popular. Tanto regimes com apenas uma instituição quanto aqueles sem nenhuma apresentam níveis de protesto significativamente mais baixos do que regimes com legislaturas multipartidárias. Regimes autoritários, com sistemas de partido único ou com uma legislatura, aparecem como a configuração institucional mais está$\mathrm{vel}^{21}$. Demandas podem ser expressas, preferências reveladas e acordos políticos alcançados por meio de legislaturas ${ }^{22}$. Em regimes de partido único, "um único partido é um instrumento através do qual o regime pode penetrar e controlar a sociedade" (Gandhi e Przeworski, 2007:1283). Além disso, amplos setores da população podem ser integrados ao que Kasza (1995) chama de "organizações de massa administradas", que são "organizações formais estruturadas e gerenciadas pelo aparato dirigente do Estado para dar forma à ação social de massa com o propósito de implementar políticas públicas" (ibidem:218). Essas organizações ampliam o controle do Estado de muitas maneiras diferentes, nomeadamente, segundo Kasza (1995): dependência material, consumo de tempo, organização do apoio, escritórios e honrarias, e administração local autodirigida. Em contrapartida, autocracias plena- 
mente institucionalizadas apresentam os mais altos níveis de mobilização da oposição. Nesse caso, a permissão de um nível limitado de autonomia organizacional por autoridades do regime dá aos membros da oposição mais espaço para organizar e coordenar grupos previamente latentes e clandestinos. Paralelamente a isso, segundo a teoria da mobilização de recursos, a possibilidade de organizar aumenta os recursos da oposição e, como resultado, seu nível de mobilização. Por outro lado, o nível de urbanização não tem poder sobre o número de manifestações, embora seu efeito possa ser capturado pelo PIB per capita.

Fatores estruturais são indiscutivelmente importantes e seguem o padrão descrito na seção Teoria e Hipóteses. As três variáveis que os capturam são significativas e têm os sinais esperados. Ter sido uma democracia e, portanto, ter herdado uma cultura democrática torna o protesto mais viável e abundante depois de estabelecida a ditadura por 0,3-0,4 ponto.

No que tange ao tempo de guerra, a atmosfera de instabilidade provocada pode fazer com que a oposição perceba que a derrubada do regime ficou mais próxima, de tal modo que ela decida aumentar o nível de protesto e, assim, de pressão sobre a elite dirigente para mudar o regime político. Finalmente, quanto mais numeroso é o principal grupo étnico, mais manifestações encontramos (ver a subseção Fatores Estruturais, p. 728).

A respeito dos modelos de Estado rentista, os resultados confirmam, pelo menos parcialmente, as afirmações básicas. A dummy do petróleo não é significativa sob qualquer especificação da equação, enquanto a dummy da exportação de minérios o é. Países exportadores de minérios (e autoritários), situados sobretudo na África, são muito instáveis em função das lutas constantes pelo controle do Estado e das rendas externas que provêm dos recursos minerais. Comportamento predatório generalizado e corrupção aumentam o descontentamento entre os cidadãos e, por conseguinte, o protesto político. Ditaduras exportadoras de petróleo podem gerar níveis mais altos de obediência em função das alíquotas de imposto menores e de seu PIB per capita muito mais elevado. Em contrapartida, os efeitos econômicos e políticos de recursos saqueáveis (crescimento lento, corrupção e personalismo), como exportações minerais, criam um campo fértil para o conflito fundado no descontentamento. 
Finalmente, a variável dependente defasada é positiva e altamente significativa (os coeficientes são sempre maiores do que 0,44 ), o que confirma a idéia de protesto como um processo autogerador de curto prazo, de modo que o nível do protesto passado influencia seu nível atual (a relação de longo prazo foi testada negativamente por Lichbach e Gurr, 1981) ${ }^{23}$.

\section{Protesto Violento: Tumultos em Regimes Autoritários}

Em Temporalidade e Relação Violência/Não-Violência (p. 723), foi suposto que a relação de substituição entre protesto não-violento e violento não podia ser bidirecional. Minha hipótese é, então, que os dois tipos de atividade caminham juntos, ou seja, estão positivamente relacionados, mas apenas em uma direção. Resumindo: o protesto não-violento será um dos principais determinantes do nível de protesto violento naquele período, medido pelo número de tumultos. A Tabela 3 mostra os coeficientes estimados dos dois tipos de modelo.

O Modelo 1 foi estimado usando a mesma especificação utilizada nos modelos para as manifestações, ou seja, os erros-padrão corrigidos por painéis com dummies para regiões ${ }^{24}$. Os resultados são muito semelhantes àqueles obtidos nos modelos para manifestações. Assim, pareceria que os dois tipos de atividade (violenta e não-violenta) derivam dos mesmos fatores explicativos, mas isso é apenas parcialmente verdadeiro. A maioria dessas variáveis está por trás das atividades violentas, mas apenas porque determinam o protesto não-violento, que é também o principal determinante dos tumultos. Comparemos, por exemplo, o $\mathrm{R}^{2}$ dos dois tipos de protesto: o $\mathrm{R}^{2}$ dos modelos de manifestação é quase o dobro do $R^{2}$ das regressões de tumulto; portanto, algo está faltando nesse modelo. Se ambas as variáveis dependentes fossem causadas absolutamente pelos mesmos fatores, esperaríamos um poder explicativo mais parecido das co-variantes do lado direito.

No Modelo 2, a variável "média regional de tumultos" por ano foi incluída para testar a presença da difusão, como foi feito no caso das manifestações. O coeficiente de 0,656 é significativo e positivo, como esperado. Outra vez, o que está ocorrendo em outros países dentro da região parece ter influência importante também sobre o protesto doméstico violento.

O número de manifestações foi incluído como variável independente no Modelo 3 (e também nos Modelos 4 e 5). A despeito da alta correla- 
ção contemporânea, as principais variáveis continuam significativas e o coeficiente do número de manifestações é positivo e significativo. Um aumento de um ponto no número de manifestações aumenta 0,54 ponto no número de tumultos, controladas as demais variáveis. O efeito do mecanismo de difusão política é ainda forte $(\beta=0,468)$. O nível de desenvolvimento não se revela significativo, embora a população urbana (como porcentagem da população total) o seja.

O Modelo 4 mostra os resultados de uma estimação de efeitos aleatórios de Mínimos Quadrados em Dois Estágios - MQ2E utilizando variáveis instrumentadas. O Modelo 5 apresenta a mesma especificação, mas usando os MQ2E dentro do estimador, ou seja, efeitos fixos ${ }^{25}$. Neles, a variável independente "manifestações" é instrumentada por sua defasagem e, como é usual, pelas restantes variáveis independentes incluídas nos modelos explicativos de tumultos.

Os modelos de MQ2E confirmam a hipótese sublinhada no início desta seção, contradizendo os resultados de Moore (1998), que apoiavam a proposição de substituição bidirecional de Lichbach (1987). “Manifestações" são um dos principais determinantes de tumultos no período corrente, mais ainda do que a variável dependente defasada. O coeficiente da variável "manifestações" é de aproximadamente 0,26 , enquanto o da defasada é de aproximadamente 0,1 (tendo em mente que ambas são medidas da mesma forma, de modo que os coeficientes são comparáveis). O que esse resultado nos diz é que os tumultos não são altamente autogeradores, mas derivam acima de tudo do protesto nãoviolento ${ }^{26}$. Note-se que a relevância explicativa de algumas das variáveis desaparece e que o $\mathrm{R}^{2}$ geral mais do que dobra.

No modelo de efeitos aleatórios (Modelo 3), em que as variáveis invariantes no tempo não são excluídas, as variáveis independentes que mantêm sua significação são: repressão (captada por expurgos); crescimento econômico; participação do governo; as instituições ditatoriais (semi-institucionalizada e não-institucionalizada); e o nível de desenvolvimento (PIB per capita).

O crescimento econômico aparece como o grande fator preventivo do protesto e da violência na medida em que tanto aumenta a renda quanto faz subirem os custos de oportunidade de tomar parte em qualquer atividade de protesto. Ao contrário, o nível de desenvolvimento não faz diferença na explicação dos episódios violentos no modelo de efeitos fixos e seu coeficiente encolhe no de efeitos aleatórios. 
Participação Arriscada: Manifestações e Tumultos em Regimes Ditatoriais

Tabela 3

Tumultos em Ditaduras: Análise Comparada de Séries Temporais

\begin{tabular}{|c|c|c|c|c|c|}
\hline \multirow[b]{2}{*}{ Variáveis Independentes } & \multicolumn{5}{|c|}{ Número de Tumultos } \\
\hline & (1) & (2) & (3) & (4) & (5) \\
\hline \multirow[t]{2}{*}{ Variável dependente defasada } & $0,256^{* * *}$ & $0,244^{* * *}$ & $0,117^{* *}$ & $0,179 * * *$ & $0,093^{* * *}$ \\
\hline & $(0,066)$ & $(0,057)$ & $(0,054)$ & $(0,020)$ & $(0,021)$ \\
\hline \multirow[t]{2}{*}{ Manifestações } & - & - & $0,540^{* * *}$ & $0,277^{* * *}$ & $0,254^{* * *}$ \\
\hline & - & - & $(0,038)$ & $(0,046)$ & $(0,063)$ \\
\hline \multirow[t]{2}{*}{ Média regional de tumultos } & - & $0,656^{* * *}$ & $0,468^{* * *}$ & $0,559 * * *$ & $0,544^{* * *}$ \\
\hline & - & $(0,086)$ & $(0,069)$ & $(0,047)$ & $(0,049)$ \\
\hline \multirow[t]{2}{*}{ Crescimento econômico } & $-0,020^{* * *}$ & $-0,017^{* * *}$ & $-0,007^{* *}$ & $-0,012^{* * *}$ & $-0,015^{* * *}$ \\
\hline & $(0,003)$ & $(0,003)$ & $(0,003)$ & $(0,004)$ & $(0,004)$ \\
\hline \multirow[t]{2}{*}{ PIB per capita } & $0,0002^{* * *}$ & $0,0002^{* * *}$ & $5,69 \mathrm{e}-06$ & $0,0001^{*}$ & 0,0000 \\
\hline & $(0,000)$ & $(0,000)$ & $(0,000)$ & $(0,000)$ & $(0,000)$ \\
\hline \multirow[t]{2}{*}{$(\mathrm{PIB} \text { per capita })^{2}$} & $-1,79 e-08^{* *}$ & $-2,46 \mathrm{e}-08^{* * *}$ & $-4,30 e-09$ & $-1,42 \mathrm{e}-08^{*}$ & $-7,02 \mathrm{e}-10$ \\
\hline & $(7,28 \mathrm{e}-09)$ & $(8,02 \mathrm{e}-09)$ & $(5,32 \mathrm{e}-09)$ & $(8,39 \mathrm{e}-09)$ & $(1,30 \mathrm{e}-08)$ \\
\hline \multirow[t]{2}{*}{ Semi-institucionalizada } & $-0,293^{* * *}$ & $-0,270^{* * *}$ & $-0,160^{* *}$ & $-0,220^{* * *}$ & $-0,083$ \\
\hline & $(0,107)$ & $(0,105)$ & $(0,080)$ & $(0,078)$ & $(0,117)$ \\
\hline \multirow[t]{2}{*}{ Não-institucionalizada } & $-0,277^{* * *}$ & $-0,232^{* *}$ & $-0,108$ & $-0,177^{* *}$ & 0,023 \\
\hline & $(0,102)$ & $(0,105)$ & $(0,080)$ & $(0,089)$ & $(0,120)$ \\
\hline \multirow[t]{2}{*}{ Grupo étnico (\%) } & $0,002^{*}$ & $0,002^{*}$ & $-0,0007$ & 0,0008 & - \\
\hline & $(0,001)$ & $(0,001)$ & $(0,001)$ & $(0,001)$ & - \\
\hline \multirow[t]{2}{*}{ População urbana (\%) } & 0,001 & $0,003^{*}$ & $0,002^{*}$ & 0,003 & $-0,014^{*}$ \\
\hline & $(0,001)$ & $(0,002)$ & $(0,001)$ & $(0,002)$ & $(0,007)$ \\
\hline \multirow[t]{2}{*}{ Expurgos } & $0,320^{* * *}$ & $0,260^{* * *}$ & $0,144^{*}$ & $0,203^{* * *}$ & $0,151^{* * *}$ \\
\hline & $(0,078)$ & $(0,096)$ & $(0,079)$ & $(0,053)$ & $(0,055)$ \\
\hline \multirow[t]{2}{*}{$(\text { Expurgos })^{2}$} & $-0,009 * * *$ & $-0,008^{* * *}$ & $-0,004^{*}$ & $-0,006^{* * *}$ & $-0,004^{* *}$ \\
\hline & $(0,002)$ & $(0,002)$ & $(0,002)$ & $(0,001)$ & $(0,002)$ \\
\hline \multirow[t]{2}{*}{ Assassinatos políticos } & $0,093^{*}$ & $0,114^{* *}$ & 0,012 & 0,062 & 0,067 \\
\hline & $(0,056)$ & $(0,057)$ & $(0,052)$ & $(0,040)$ & $(0,042)$ \\
\hline \multirow[t]{2}{*}{ Participação do governo } & $-0,012^{* * *}$ & $-0,013^{* * *}$ & $-0,008^{* * *}$ & $-0,010^{* * *}$ & $-0,006$ \\
\hline & $(0,002)$ & $(0,002)$ & $(0,002)$ & $(0,003)$ & $(0,006)$ \\
\hline \multirow[t]{2}{*}{ Democracia prévia } & $0,189^{* *}$ & 0,160 & $-0,102$ & 0,029 & $-0,007$ \\
\hline & $(0,088)$ & $(0,112)$ & $(0,084)$ & $(0,085)$ & $(0,307)$ \\
\hline \multirow[t]{2}{*}{ Dummy de guerra } & $0,241^{* *}$ & 0,195 & 0,106 & 0,147 & $0,287^{* *}$ \\
\hline & $(0,114)$ & $(0,119)$ & $(0,105)$ & $(0,094)$ & $(0,118)$ \\
\hline \multirow[t]{2}{*}{ País exportador de minério } & 0,059 & 0,081 & $-0,038$ & 0,015 & - \\
\hline & $(0,070)$ & $(0,069)$ & $(0,067)$ & $(0,098)$ & - \\
\hline Dummies de região & $\operatorname{sim}$ & $\operatorname{sim}$ & $\operatorname{sim}$ & $\operatorname{sim}$ & não \\
\hline
\end{tabular}


Tabela 3

Tumultos em Ditaduras: Análise Comparada de Séries Temporais (continuação)

\begin{tabular}{l|c|c|c|c|c}
\hline \multirow{2}{*}{ Variáveis Independentes } & \multicolumn{5}{|c}{ Número de Tumultos } \\
\cline { 2 - 6 } & $\mathbf{( 1 )}$ & $\mathbf{( 2 )}$ & $\mathbf{( 3 )}$ & $\mathbf{( 4 )}$ & (5) \\
\hline $\mathrm{R}^{2}$ & 0,1666 & 0,2285 & 0,4878 & 0,4407 & 0,3691 \\
Wald Chi $^{2}$ & 224,12 & 331,48 & 578,37 & 846,74 & 631,93 \\
Observações & 2.305 & 2.082 & 2.081 & 2.055 & 2.055 \\
\hline
\end{tabular}

Erro padrão entre parênteses; $* * * p<0,01 ; * * p<0,05 ; * p<0,10$.

Tipo de regime omitido é "plenamente institucionalizado".

Elaboração do autor.

Surpreendentemente, a curva em U invertido para a variável repressão vale para tumultos; portanto, a repressão não é apenas relevante para explicar manifestações, mas também para determinar os níveis de violência que podem ocorrer uma vez iniciada a dissensão. Por outro lado, o padrão encontrado para as instituições nos modelos das manifestações também se faz presente aqui, ou seja, as ditaduras que experimentam os níveis mais baixos de conflito são aquelas semi-institucionalizadas, enquanto aquelas plenamente institucionalizadas (com múltiplos partidos no Legislativo) apresentam os níveis mais elevados de atividades participativas. O governo também pode desempenhar outro papel ativo e direto na moderação da violência, aumentando o nível de redistribuição, como mostra claramente o coeficiente, negativo e significativo, da participação governamental, de -0,010. Finalmente, a instabilidade e a fraqueza do regime, provocadas pela guerra, aumentam o número de protestos violentos, mas não são significativas.

Os modelos de efeitos fixos produzem resultados que são ligeiramente diferentes daqueles que obtivemos do modelo de efeitos aleatórios; além disso, como foi dito, têm a desvantagem de excluir as variáveis independentes invariantes no tempo. A maior divergência entre os dois modelos é que, no de efeitos fixos, uma das variáveis para as instituições ditatoriais não é significativa, assim como o nível de desenvolvimento. Os demais coeficientes, que já eram significativos, têm os mesmos sinais.

\section{CONSIDERAÇÕES FINAIS}

A participação é uma característica-chave em regimes democráticos, pois o povo tem o direito de protestar e de expressar sua opinião. No entanto, regimes não-democráticos ainda dominam grande parcela da 
população do mundo que, em conseqüência, não pode viver e se expressar de maneira inteiramente livre. De qualquer modo, pessoas que vivem nesses regimes protestam, algumas vezes pacificamente, outras violentamente. Este artigo tratou de explicitar sob que condições as pessoas participam em regimes autoritários, descrevendo modelos explicativos tanto para protesto violento quanto para não-violento.

A fim de testar as teorias e hipóteses em relação ao dissenso popular, um grande número de dados comparativos em séries temporais foi montado, contendo mais de cem países e 120 regimes autoritários para o período entre 1950 e 1990.

Os resultados dos modelos de regressão confirmam as hipóteses principais. O simples modelo econômico desenvolvido na seção intitulada Condições Econômicas e Sociais (p. 724) foi amplamente confirmado. O crescimento econômico reduz tanto o protesto não-violento quanto o violento, aumentando os custos de oportunidade dessas atividades e a renda disponível do povo, em uma relação de curva em U invertido entre o número de manifestações e o PIB per capita (ou seja, o desenvolvimento econômico), que apóia tanto as proposições dos modelos quanto a versão mais simples da teoria da privação relativa. Esta afirma que, como a desigualdade é maior nos países de médio desenvolvimento cuja participação do setor industrial é o principal componente do PIB, é nesses países que os conflitos distribucionais surgem com maior probabilidade e, com eles, o dissenso e o protesto popular. Finalmente, o papel redistributivo do Estado é também importante para a redução do conflito. A redistribuição foi medida pela participação real do governo como porcentagem do PIB e seu coeficiente é negativo, o que reduz o dissenso, e altamente significativo tanto nos modelos de protesto violento quanto nos não-violentos. Por outro lado, teorias da desorganização social foram totalmente rejeitadas depois da análise empírica.

Instituições ditatoriais são criadas para cooptar, mas, ao mesmo tempo, como permitem que a oposição se organize, o conflito e o dissenso podem se alastrar. As ditaduras mais eficazes são as semi-institucionalizadas, ou seja, aquelas com apenas um partido e/ou uma legislatura; nesse caso, o papel encapsulador dessas trincheiras pseudodemocráticas é desempenhado de modo eficaz. Em regimes plenamente institucionalizados, à medida que a tolerância aumenta e a força e os recursos organizacionais da oposição são superiores, o número de atividades 
de participação é significativamente mais alto do que nas outras duas categorias.

Sobre a relação repressão/dissenso, os resultados apóiam as conclusões alcançadas por Gupta, Singh e Sprague (1993) de que há uma relação de curva em U invertido entre essas duas variáveis em regimes autoritários. Essa conclusão vale tanto para ações não-violentas quanto violentas. Além disso, tanto as manifestações quanto os tumultos são processos autogeradores cujos níveis atuais dependem dos níveis passados, mas essa relação é mais forte no caso das manifestações. A razão é que o número atual de tumultos é determinado sobretudo pelos níveis atuais de manifestações, ou seja, há uma forte relação positiva entre eles.

O que acontece em outros países da mesma região geográfica é também um importante determinante dos níveis de protesto. Parece haver algum tipo de efeito contágio, ou bola de neve, pelo menos no âmbito regional. O número médio de manifestações e tumultos por ano dentro de uma região tem um efeito importante e positivo sobre o nível de protesto em um dado país.

Os assim chamados efeitos estruturais também se provaram importantes na determinação dos níveis de protesto. Ter sido uma democracia aumenta o número de manifestações. Ser uma ditadura exportadora de minérios também aumenta o dissenso; ao contrário, a dummy de exportação de petróleo não é significativa. Finalmente, períodos de guerra são também períodos de protesto e tumultos. Além de enfraquecer a capacidade de controle do Estado (uma vez que grande parte dos recursos é necessária para a luta), a guerra pode tornar a mudança de regime aparentemente mais provável e, com isso, fomentar as atividades de participação.

(Recebido para publicação em julho de 2006)

(Versão definitiva em novembro de 2007) 


\section{NOTAS}

1. Em algumas delas é somente uma pessoa que controla todo o poder, por exemplo, o caudilho, o Führer, o Duce, o rei, e assim por diante; em outras, porém, o poder é compartilhado por um pequeno grupo de pessoas, por exemplo, Juntas Militares, Politburos, Conselhos de Salvação Nacional etc.

2. Sobre os limites probabilísticos ao poder e à atividade predatória dos ditadores, ver, por exemplo, Acemoglu e Robinson (2005), Findlay (1990), Grossman e Noh (1994) e Robinson (2000).

3. Neste artigo, não será feita a distinção entre os conceitos de ditadura, "regime autoritário" e "regime autocrático", considerando, então, que todos eles se referem ao mesmo conceito: regimes não-democráticos.

4. Os dados e variáveis dependentes serão descritos a seguir.

5. Ver também Bertocchi e Spagat (2001) para um modelo formal de cooptação e para uma aplicação ao caso das privatizações pós-comunistas.

6. Ver também Muller e Weede (1990).

7. Os casos de que extraiu seus dados de séries temporais são: a República Democrática Alemã, a Tchecoslováquia e a Intifada Palestina. Para um belo estudo da Europa Oriental em 1989, ver Karklins e Petersen (1993).

8. Aqui utilizo a codificação de regimes realizada por Przeworski et alii (2000) tomando apenas aqueles codificados como "ditaduras" em seu conjunto de dados.

9. Para um uso mais recente das relações de curto e longo prazos entre repressão e dissensão no caso da Revolução Iraniana, ver Rasler (1996). Usando modelos Poisson de regressão, ele mostra que a repressão tinha um efeito negativo de curto prazo e um efeito positivo de longo prazo sobre os níveis totais de protesto por meio da influência da repressão sobre a difusão espacial.

10. Isso implicaria impor uma alíquota de imposto mais alta (digamos, $\left.\tau^{\prime}\right)$ e, portanto, mais redistribuição do que no governo autoritário ou em um Estado pós-revolucionário, em que os recursos são distribuídos entre os pobres. Ver Boix (2003) para um modelo da teoria dos jogos completo e abrangente sobre as conseqüências distribucionais de regimes políticos e transições para a democracia.

11. É fácil ver que $y_{p}=\frac{Y_{p}}{1-\theta}$, e que $y_{a}$ é a renda média.

12. Os únicos dados que temos sobre desigualdade (medida usando um índice de Gini) em um formato de séries temporais comparadas são os de Deininger e Squire (1996), mas seu grau de confiabilidade é controverso. Por isso, o PIB per capita será utilizado como melhor indicador indireto.

13. Ver, entre outros, Collier e Hoeffler (2002) e Humphreys (2005).

14. Para uma avaliação crítica da teoria do Estado rentista, ver Dijohn (2002).

15. Sobre difusão e comunicação, ver, por exemplo, Myers (2000).

16. Base de dados desenvolvida por Przeworski et alii (2000).

17. Embora não apresentada aqui, a variável "crescimento da população" foi também incluída em alguns dos modelos a fim de testar a validez da teoria da desorganização social. Os coeficientes obtidos não foram significativos em nenhum desses modelos e, levando em consideração o sinal negativo da variável "crescimento econômico", a 


\section{Abel Escribà-Folch}

teoria da desorganização social não é suportada pela grande base de dados nem pelas análises empíricas. Uma variável dummy para a ocorrência de qualquer tipo de eleição foi também incluída para testar se poderia gerar protesto contra os resultados (sempre favorável para o autocrata em exercício), mas não foi significativa, nem com defasagem.

18. Davis (1999) trata de testar mais amplamente essas teorias incluindo, de um lado, interações entre os níveis educacionais, o índice de direitos políticos e o nível de desenvolvimento; de outro, entre o nível de desenvolvimento e o índice de direitos políticos. Nenhum deles é estatisticamente significativo em sua análise. Sua hipótese é a de que a privação e, depois, o conflito apareceriam sobretudo "quando uma população que é relativamente rica e bem-educada é confrontada com um sistema político repressivo e autocrático" (ibidem:13).

19. Isso implicaria um aumento de $p$ (probabilidade de mudança) na especificação básica.

20. Lembre-se de que a categoria de referência é a ditadura plenamente institucionalizada.

21. Ver, por exemplo, Brooker (1995) para alguns estudos concretos de Estados de partido único.

22. Em sua análise do Soviete Supremo, Vanneman afirma que, no âmbito legislativo, o sistema de subcomissões recentemente criado se tornou "um meio eficaz de combinar amostragem de opinião pública com amostragem de especialização" (1977:162).

23. O modelo foi também computado incluindo mais defasagens, mas não foram significativas.

24. Não apresentei os coeficientes para essas dummies na tabela. As duas regiões que são estatisticamente significativas são a África e o sul da Ásia.

25. Esse tipo de estimativa exclui variáveis invariantes no tempo. Portanto, "grupo étnico" e "país exportador de minério" não foram computados.

26. Modelo alternativo foi também testado usando MQ2E, em que "manifestações" era a variável dependente e "tumultos" uma das independentes (instrumentada). Os resultados mostraram que "tumultos" não tinham influência sobre "manifestações", confirmando a direção causal proposta neste texto. 


\section{REFERÊNCIAS BIBLIOGRÁFICAS}

ACEMOGLU, Daron e ROBINSON, James A. (2005), Economic Origins of Dictatorship and Democracy. New York, Cambridge University Press.

AUVINEN, Juha. (1997), "Political Conflict in Less Developed Countries 1981-89". Journal of Peace Research, vol. 34, № 2, pp. 177-195.

BANKS, Arthur S. (1996), Cross-National Time-Series Data Archive. Binghamton, NY, Center for Social Analysis, State University of New York at Binghamton.

BECK, Nathaniel e KATZ, Jonathan N. (1995), “What to Do (and Not to Do) with Time-Series Cross-Section Data". American Political Science Review, vol. 89, no 3, pp. 634-647.

BERTOCCHI, Graziella e SPAGAT, Michael. (2001), “The Politics of Co-Optation”. Journal of Comparative Economics, vol. 29, no 4, pp. 591-607.

BOIX, Carles. (2003), Democracy and Redistribution. New York, Cambridge University Press.

(2004), Political Violence. Trabalho apresentado na conferência Order, Conflict and Violence, Yale University, 30 de abril-1ㅇ de maio.

BRATTON, Michael e VAN DE WALLE, Nicolas. (1997), Democratic Experiments in Africa. Regime Transitions in Comparative Perspective. New York, Cambridge University Press.

BROOKER, Paul. (1995), Twentieth-Century Dictatorships: The Ideological One-Party States. Basingstoke, Macmillan.

COLLIER, Paul e HOEFFLER, Anke. (2002), “Greed and Grievance in Civil War”. Working Paper, no 2002-01, Centre for the Study of African Economies, Oxford University.

DAVIS, Gareth G. (1999), “Repression, Rationality and Relative Deprivation: A Theoretical and Empirical Examination of Cross-National Variations in Political Violence". Working Paper, no 99.04, Department of Economics, George Mason University.

DEININGER, Klaus e SQUIRE, Lyn. (1996), “A New Dataset Measuring Income Inequality". World Bank Economic Review, vol. 10, no 3, pp. 565-591.

DIJOHN, Jonathan. (2002), "Mineral-Resource Abundance and Violent Political Conflict: A Critical Assessment of the Rentier State Model". Working Paper, no 20, Crisis States Programme, London School of Economics and Political Science, University of London.

FEIERABEND, Rosalind L., FEIERABEND, Ivo K. e GURR, Ted R. (eds.). (1972), Anger, Violence and Politics. Englewood Cliffs, Prentice Hall.

FINDLAY, Ronald. (1990), “The New Political Economy: Its Explanatory Power for LDC's". Economics \& Politics, vol. 2, pp. 193-221.

FRANCISCO, Ronald A. (1995), "The Relationship between Coercion and Protest: An Empirical Evaluation in Three Coercive States". Journal of Conflict Resolution, vol. 39, no 2, pp. 263-282.

GANDHI, Jennifer e PRZEWORSKI, Adam. (2006), “Cooperation, Cooptation, and Rebellion under Dictatorships". Economics \& Politics, vol. 18, no 1, pp. 1-26. 


\section{Abel Escribà-Folch}

(2007), "Authoritarian Institutions and the Survival of Autocrats". Comparative Political Studies, vol. 40, no 11, pp. 1279-1301.

GROSSMAN, Herschel I. (1991), "A General Equilibrium Model of Insurrections". American Economic Review, vol. 81, no 4, pp. 912-921.

e NOH, Suk Jae. (1994), “Proprietary Public Finance and Economic Welfare”. Journal of Public Economics, vol. 53, no 2, pp. 187-204.

GUPTA, Dipak K., SINGH, Harinder e SPRAGUE, Tom. (1993), “Government Coercion of Dissidents: Deterrence or Provocation?". Journal of Conflict Resolution, vol. 37, no 2, pp. 301-339.

GURR, Ted R. (1970), Why Men Rebel. Princeton, Princeton University Press.

e DUVALL, R. (1973), “Civil Conflict in the 1960s: A Reciprocal Theoretical System with Parameter Estimates". Comparative Political Studies, vol. 6, pp. 135-169.

HUMPHREYS, Macartan. (2005), “Natural Resources, Conflict, and Conflict Resolution". Journal of Conflict Resolution, vol. 49, no 4, pp. 508-537.

HUNTINGTON, Samuel P. (1968), Political Order in Changing Societies. New Haven, Yale University Press.

JENKINS, J. Craig. (1983), "Resource Mobilization Theory and the Study of Social Movements". Annual Review of Sociology, vol. 9, pp. 527-553.

KARKLINS, Rasma e PETERSEN, Roger. (1993), “Decision Calculus of Protesters and Regimes: Eastern Europe 1989". Journal of Politics, vol. 55, no 3, pp. 588-614.

KARL, Terry Lynn. (1997), The Paradox of Plenty: Oil Booms and Petro-States. Berkeley, University of California Press.

KASZA, Gregory J. (1995), "Weapons of the Strong: Organization and Terror", in H. E. Chehabi e A. Stepan (orgs.), Politics, Society, and Democracy. Comparative Studies. Boulder, Westview.

KURAN, Timur. (1995), Private Truths, Public Lies: The Social Consequences of Preference Falsification. Cambridge, Harvard University Press.

LICHBACH, Mark. (1987), “Deterrence or Escalation? The Puzzle of Aggregate Studies of Repression and Dissent". Journal of Conflict Resolution, vol. 31, no 2, pp. 266-297.

e GURR, Ted R. (1981), “The Conflict Process: A Formal Model”. Journal of Conflict Resolution, vol. 25, no 1, pp. 3-29.

MOORE, Will H. (1998), "Repression and Dissent: Substitution, Context, and Timing". American Journal of Political Science, vol. 42, no 3, pp. 851-873.

MULLER, Edward N. e WEEDE, Erich. (1990), “Cross-National Variation in Political Violence: A Rational Action Approach". Journal of Conflict Resolution, vol. 34, no 4, pp. 624-651.

MYERS, Daniel J. (2000), Media, Communication Technology, and Protest Waves. Trabalho apresentado na conferência Social Movement Analysis: The Network Perspective, Ross Priory, Scotland, 22-25 de junho.

OKRUHLIK, Gwenn. (1999), "Rentier Wealth, Unruly Law, and the Rise of Opposition. The Political Economy of Oil States". Comparative Politics, vol. 31, no 3, pp. 295-315. 
OLIVER, Pamela E. e MYERS, Daniel J. (1998), Diffusion Models of Cycles of Protest as a Theory of Social Movements. Trabalho apresentado nos Encontros Trienais da International Sociological Association - ISA, Research Committee 48, Social Movements, Collective Action, and Social Change. Montreal, Canadá, 26 de julho-1o de agosto.

OLSON, Mancur. (1963), "Rapid Growth as a Destabilizing Force". Journal of Economic History, vol. 23, no 4, pp. 529-552.

PRZEWORSKI, Adam et alii. (2000), Democracy and Development. Political Institutions and Well-Being in the World, 1950-1990. New York, Cambridge University Press.

RASLER, Karen. (1996), “Concessions, Repression, and Political Protest in the Iranian Revolution". American Sociological Review, vol. 61, no 1, pp. 132-152.

ROBINSON, James A. (2000), When is a State Predatory? University of California at Berkeley. Manuscrito.

ROSE, Richard e MISHLER, William. (2002), "Comparing Regime Support in Non-Democratic and Democratic Countries". Democratization, vol. 9, no 2, pp. 1-20.

SCHNYTZER, Adi e ŠUŠTERŠIČ, Janez. (1998), "Why Join the Party in a One-Party System?: Popularity versus Political Exchange". Public Choice, vol. 94, nos 1-2, pp. 117-134.

SMITH, Benjamin. (2004), "Oil Wealth and Regime Survival in the Developing World, 1960-1999". American Journal of Political Science, vol. 48, no 2, pp. 232-246.

THE WORLD BANK. (2000), World Development Indicators. Washington, D.C., World Bank.

TILLY, Charles. (1978), From Mobilization to Revolution. Reading, Addison-Wesley.

TULLOCK, Gordon. (1974), The Social Dilemma: The Economics of War and Revolution. Blacksburg, Center for the Study of Public Choice.

VANNEMAN, Peter. (1977), The Supreme Soviet: Politics and the Legislative Process in the Soviet Political System. Durham, Duke University Press.

WINTROBE, Ronald. (1998), The Political Economy of Dictatorship. New York, Cambridge University Press. 


\section{ABSTRACT \\ High-Risk Political Participation: Demonstrations and Riots under Dictatorial Regimes}

This article draws on a broad sample of countries to empirically test the different theories on dissent and protest in the context of authoritarian regimes, where such activities are generally repressed and are therefore risky. The empirical results of the longitudinal comparative analysis basically confirm the predictions of the rational economic approach to political protest as well as the explanatory power of structural factors, the relative deprivation theory, the political diffusion processes (at the regional level), the role of dictatorial institutions, and in part the resource mobilization theory. The empirical analysis also shows that non-violent participation is one of the main determinants of riots and that past protest is important in determining present protest (whatever its type).

Key words: political protest; authoritarian regimes; institutions; political participation

RÉSUMÉ

Participation Politique Périlleuse: Manifestations et Troubles sous des Régimes Dictatoriaux

Dans cet article, on contrôle de façon empirique, tout en utilisant un large échantillon de pays, les différentes théories sur dissension et protestation au coeur des régimes autoritaires, où ces activités sont souvent traquées et forcément périlleuses. Les résultats empiriques de l'analyse comparative longitudinale confirment les prévisions de l'approche économique rationnelle à propos de la protestation politique, ainsi que le pouvoir d'explication des facteurs structuraux, de la théorie de la privation relative, des processus de diffusion politique au niveau des régions, le rôle des institutions dictatoriales et, en partie, la théorie de la mobilisation des ressources. On voit aussi que la participation non violente est l'un des principaux déterminants des émeutes et que la protestation précédente détermine de façon décisive la protestation actuelle, quelle qu'elle soit.

Mots-clé: protestation politique; régimes autoritaires; institutions; participation politique 